\title{
ANALYSIS OF TRANSIENT SEEPAGE INTO EQUALLY SPACED DITCH DRAINS FROM A PONDED FIELD
}

\author{
G. BARUA ${ }^{1} \&$ W. ALAM ${ }^{2}$ \\ ${ }^{1}$ Department of Civil Engineering, Indian Institute of Technology Guwahati, Guwahati 781 039, Assam, India. \\ ${ }^{2}$ Formerly Research Scholar, Department of Civil Engineering, Indian Institute of Technology Guwahati, \\ Guwahati 781 039, Assam, India.
}

\begin{abstract}
An analytical solution is proposed for simulating transient seepage into a system of ditch drains placed in parallel in a homogeneous and anisotropic soil confined by an impermeable layer and receiving water from an infinitely extended ponded field. The solution assumes the ponding depth over the surface of the soil to be uniform and the soil fluid to be of constant density. The model can be applied for both equal and unequal water levels in adjacent drains. The accuracy of the developed solution is checked by comparing for a flow situation the hydraulic heads and streamlines as obtained from the proposed model with the corresponding results obtained from an available steady state solution of the problem as provided by Kirkham [14]. A numerical check on the proposed solution is also performed for a particular flow configuration of the problem in the transient zone. The study shows that flow in a ponded ditch drainage system is greatly influenced by anisotropy and directional conductivities of soils. The uniformity of surface flux distribution is found to be quite sensitive to the anisotropy ratio (the ratio of horizontal and vertical saturated hydraulic conductivities of soil) of a soil column - a higher anisotropy ratio favors and a low anisotropy ratio weakens this distribution. Furthermore, the time to attain steady state by a ditch drainage system can be considerable, particularly for situations where the drains are dug relatively deeper into a soil having a high anisotropy ratio. The analytical model presented here is significant as it can be used to design ditch drainage networks for reclaiming a salt-affected and/or waterlogged soil within a specified time.
\end{abstract}

Keywords: Analytical solution, anisotropy ratio, ditch drains, hydraulic conductivity, specific storage, transient seepage.

\section{INTRODUCTION}

For sustainable irrigated agriculture, it is essential that the salt put into the agricultural fields along with irrigation water must be successfully removed from the root zone of plants and the waterlogging resulting from irrigation be suitably controlled from the irrigated fields as otherwise considerable loss of productivity may occur [1-3]. Irrigation in India has been reported to cause waterlogging and salinity in many parts of the country $[1,2]$. One of the ways of reclaiming a saltaffected cropped field is to artificially subject the surface of the field to a ponding depth of good-quality irrigation water with the help of embankments so that water is forced to infiltrate through the root zone of crops and in the process washes away a part of the salt present in the soil profile; the washed salts are then drained with the help of a network of subsurface drains installed for the purpose [4-9 - to name a few]. For relatively flat agricultural fields with low soil conductivity, open drains may be suitably employed to collect and remove leached water from the fields [7]. Subsurface drainage is also used to reinstate a flooded field within a desired time and to maintain a proper water balance in paddy fields $[8,10]$. Several mathematical models have been formulated in the past to study the hydraulics of flow associated with a ditch drainage system receiving water from a ponded field. Treating the ponded ditch drainage problem as a limiting case of the auger hole problem considered by Kirkham and van Bavel [11], Kirkham [12] provided an analytical steady state solution to the ponded ditch problem for the case when the depth of ponded water at the surface of the soil is taken as zero and when the drains are being installed all the way up to an impervious barrier. Fukuda [13] applied conformal transformation to work out a steady-state analytical model for 
the partially penetrating ditch problem by assuming the depth of ponded water at the surface to be zero at all times and by neglecting the width of the suspended trenches. Using the Fourier series approach, a relatively general steady state solution to the fully penetrating ditch drainage problem was obtained by Kirkham [14], which can account for both equal as well as unequal water level heights in between the adjacent drains and a non-zero ponding depth at the surface of the soil. For a fully or partially penetrating ditch drainage system running full upto the soil surface or higher at all times, a conformal mapping solution to the problem was obtained by Warrick and Kirkham [15] by representing the ditch faces with suitable equipotentials. Youngs [16] used conformal mapping to predict steady seepage into a ditch drain of negligible width in a homogeneous soil receiving water from a ponded field of zero depth both for the cases when the drain fully penetrates the soil and rests on an impervious barrier and when there exists an infinitely deep soil layer below the base of the drain. By performing a suitable domain discretization of the flow domain, Barua and Tiwari [17] obtained a detailed solution to the steady-state partially penetrating ditch drainage problem using the Fourier series approach. This solution can account for finite width and partial penetration of the ditch drains, zero as well as non-zero depth of ponding at the surface of the soil, anisotropy of the soil, and a finite depth impervious substratum below the bottom of the ditch drains. Chahar and Vadodaria $[2,3,18]$ revisited the ponded ditch problem and provided conformal mapping solutions to the problem both for the cases when the trenches fully penetrate a phreatic aquifer underlain by an impervious barrier and when they remain suspended above the impervious barrier.

All the solutions of the ditch drainage problem as mentioned earlier are for the steady-state situation and as such these solutions cannot be used for analyzing the flow behaviour of a ponded ditch drainage system under transient conditions. A comprehensive analytical treatment to the transient ditch drainage problem was provided by Barua and Alam [19] by considering a variable ponding field over the surface of the soil and unequal water level heights in between the adjacent drains. The application of this solution, however, is computationally demanding as the solution requires evaluation of three Fourier coefficient sets related to the three boundaries associated with the face of the ditches and to the surface of the soil, along with the estimation of a double Fourier series related to the initial condition of the problem. Barua and Alam [20] also provided a relatively simple analytical model to the transient ditch drainage problem by considering equal water level heights in between the adjacent drains and a uniform depth of ponding at the surface of the soil. The advantage of this solution over that of the generalized solution of Barua and Alam [19] is its computational simplicity but the flip side is that, because of the inability of this solution to account for unequal water level heights in between the drains, drainage networks based on this solution will have a comparatively lesser control on the leaching procedure of a salt-affected soil in comparison to the designs based on the general solution. Thus, there lies a need for developing a somewhat simpler mathematical model for the transient ditch problem, which can account for a constant ponding field over the surface of the soil and which can also consider at the same time the unequal water level heights in between the adjacent ditches. Such a solution, once developed, is expected to find ready uses in actual field situations over that of the simpler model presented by Barua and Alam [20] owing to its ability to account for unequal water level heights in between the drains. This is because a ponded drainage model with unequal water level heights in between the adjacent drains allows a greater control on the leaching procedure of a salt-affected soil in comparison to a model developed on the basis of an equal water level height in the drains. Moreover, as imposition of a variable ponding field at the surface of a soil column may prove to be quite difficult and/or expensive in many a field situations, a relatively simpler model of the ponded ditch drainage system may have a wider acceptability in its use in controlling saline soils as compared to the use of the general solution developed by Barua and Alam [19]. Thus, there lies a necessity of developing a suitable transient analytical model of the fully 
penetrating ditch drainage problem subjected to a uniform depth of ponding at the surface of the soil and equal or unequal water level heights in between the adjacent drains. This article tries to address this need.

\section{MATHEMATICAL FORMULATION AND SOLUTION}

Figure 1 shows the geometry of the ditch drainage problem under consideration. A homogeneous and anisotropic soil of infinite extent in the horizontal direction is drained by an array of parallel and equally spaced subsurface ditch drains receiving water from the top of the field. The ponding depth over the surface of the soil is considered as uniform and is taken as $\delta_{0}$. The depth of the impervious barrier and the levels of water in the left and the right ditches are taken as $h, H_{1}$ and $H_{3}$, respectively, all the distances being measured with respect to the origin $O$ as shown in the figure. The saturated hydraulic conductivities of the soil in the horizontal and vertical directions are designated as $K_{x}$ and $K_{y}$, respectively, and the specific storage of the soil as $S_{s}$. The spacing between the adjacent drains is taken as $S_{a}$. The ponded water is prevented from flowing directly to the ditches with the help of ditch banks of width $\varepsilon_{a}$, as can be seen in Fig. 1. For mathematical convenience, the $x$-axis is considered to be positive towards the right of the origin $O$ and the $y$-axis to be positive vertically downward from the origin $O$. As may be observed, unlike the problem considered by Barua and Alam [20] where the water levels in all the ditches were assumed to be of equal height, the water level heights in between the adjacent drains are now not taken as equal. Denoting the time variable as $t$ and the hydraulic head function as $\varphi$, the initial and boundary conditions pertaining to the region $O A B C D E F G O$ of Fig. 1 can be expressed as follows:

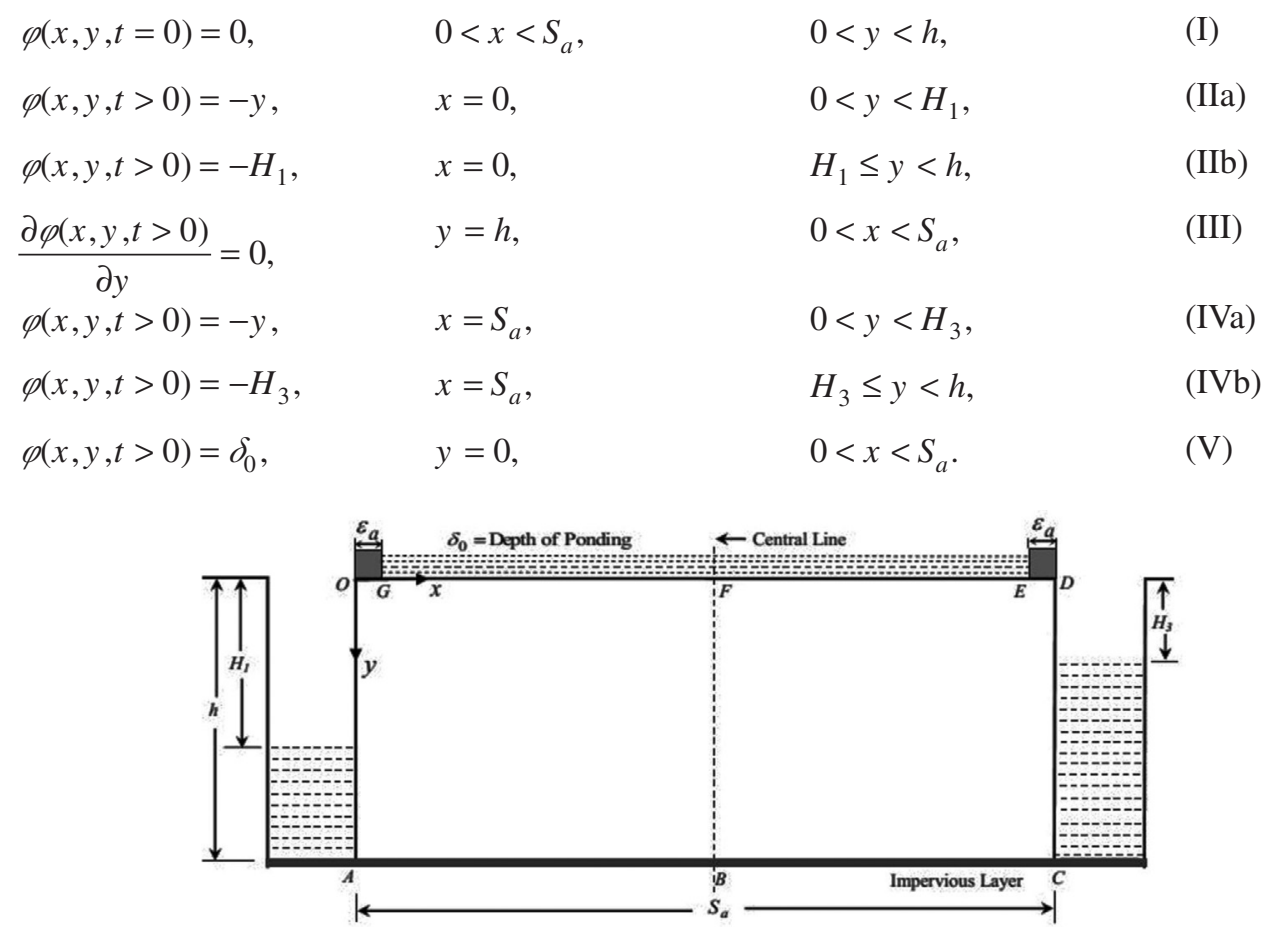

Figure 1: Geometry of a fully penetrating ditch drainage system with unequal water level heights in between adjacent drains and subjected to a uniform depth of ponding at the surface of the soil. 
A suitable hydraulic head function $\varphi$ is sought such that this function satisfies the following continuity equation corresponding to two-dimensional transient constant density groundwater flow in a homogeneous, anisotropic and compressible soil

$$
\left(\frac{K_{x}}{K_{y}}\right) \frac{\partial^{2} \varphi}{\partial x^{2}}+\frac{\partial^{2} \varphi}{\partial y^{2}}=\left(\frac{S_{s}}{K_{y}}\right)\left(\frac{\partial \varphi}{\partial t}\right),
$$

along with the initial and boundary conditions as mentioned earlier. In order that the governing equation becomes readily amenable for mathematical treatment, the following transformation

$$
X=\left(K_{y} / K_{x}\right)^{1 / 2} x
$$

may be applied on the horizontal axis; the governing equation then reduces to the form

$$
\frac{\partial^{2} \varphi}{\partial X^{2}}+\frac{\partial^{2} \varphi}{\partial y^{2}}=\left(K_{1}\right)^{2}\left(\frac{\partial \varphi}{\partial t}\right)
$$

where

$$
\left(K_{1}\right)^{2}=S_{s} / K_{y}
$$

Applying the separation of variable method [21], a solution of eqn (3) in the computational space can be expressed as

$$
\begin{aligned}
\varphi= & \sum_{q=1}^{Q} B_{q} \frac{\sinh \left(N_{q} X\right)}{\sinh \left(N_{q} S\right)} \sin \left(N_{q} y\right)+\sum_{p=1}^{P} C_{p} \frac{\sinh \left[N_{p}(S-X)\right]}{\sinh \left(N_{p} S\right)} \sin \left(N_{p} y\right) \\
& +\sum_{m=1}^{M} \sum_{n=1}^{N} A_{m n} \sin \left(N_{m} X\right) \sin \left(N_{n} y\right) \exp \left[\frac{-\left(\lambda_{m n}\right)^{2} t}{\left(K_{1}\right)^{2}}\right]+\delta_{0},
\end{aligned}
$$

where

$$
\begin{gathered}
S=\left(\sqrt{\frac{K_{y}}{K_{x}}}\right) S_{a}, \\
N_{m}=\left(\frac{m \pi}{S}\right), \\
N_{n}=\left[\left(\frac{1-2 n}{2}\right) \frac{\pi}{h}\right], \\
N_{p}=\left[\left(\frac{1-2 p}{2}\right) \frac{\pi}{h}\right], \\
N_{q}=\left[\left(\frac{1-2 q}{2}\right) \frac{\pi}{h}\right],
\end{gathered}
$$




$$
\left(\lambda_{m n}\right)^{2}=\left(N_{m}\right)^{2}+\left(N_{n}\right)^{2}
$$

and $M, N, P$ and $Q$ are all integers tending to infinity.

From eqn (5), it can be seen that the defined hydraulic head function already satisfies boundary conditions III and V; the remaining boundary conditions IIa, IIb, IVa, and IVb and the initial condition I will now be used to evaluate the constants of eqn (5). Application of IIa and IIb to eqn (5) (after first converting them from the real to the computational space) yields

$$
\begin{aligned}
& \sum_{p=1}^{P} C_{p} \sin \left(N_{p} y\right)=-\delta_{0}-y, \quad 0<y<H_{1}, \\
& \sum_{p=1}^{P} C_{p} \sin \left(N_{p} y\right)=-\delta_{0}-H_{1}, \quad H_{1} \leq y<h .
\end{aligned}
$$

$C_{p}$, thus, can be estimated by running a Fourier series in the interval $0<y<h$; the resultant expression for the same can be given as

$$
C_{p}=\frac{2}{h}\left[\int_{0}^{H_{1}}\left(-\delta_{0}-y\right) \sin \left(N_{p} y\right) d y+\int_{H_{1}}^{h}\left(-\delta_{0}-H_{1}\right) \sin \left(N_{p} y\right) d y\right] .
$$

eqn (12), upon simplification, gives

$$
C_{p}=\left(\frac{-2 \delta_{0}}{h N_{p}}\right)-\left(\frac{2}{h}\right)\left[\frac{\sin \left(N_{p} H_{1}\right)}{\left(N_{p}\right)^{2}}\right] .
$$

In the same way, the application of boundary conditions IVa and IVb to eqn (5) yields

$$
B_{q}=\left(\frac{-2 \delta_{0}}{h N_{q}}\right)-\left(\frac{2}{h}\right)\left[\frac{\sin \left(N_{q} H_{3}\right)}{\left(N_{q}\right)^{2}}\right] .
$$

To evaluate $A_{m n}$, the initial condition I can be applied in the transformed space to eqn (5) - the resultant expression turns out to be

$$
\begin{aligned}
\sum_{m=1}^{M} \sum_{n=1}^{N} A_{m n} \sin \left(N_{m} X\right) \sin \left(N_{n} y\right)= & -\delta_{0}-\sum_{q=1}^{Q} B_{q} \frac{\sinh \left(N_{q} X\right)}{\sinh \left(N_{q} S\right)} \sin \left(N_{q} y\right) \\
& -\sum_{p=1}^{P} C_{p} \frac{\sinh \left[N_{p}(S-X)\right]}{\sinh \left(N_{p} S\right)} \sin \left(N_{p} y\right) .
\end{aligned}
$$

The constants $A_{m n}$ can thus be evaluated by running a double Fourier series on the domain encompassed by $0<X<S$ and $0<y<h$; the pertinent expression for the same can be written as 


$$
\begin{aligned}
A_{m n}= & -\left(\frac{2}{h}\right)\left(\frac{2}{S}\right)\left[\int_{y=0}^{y=h} \int_{X=0}^{X=S}\left(\delta_{0}\right) \sin \left(N_{m} X\right) \sin \left(N_{n} y\right) d X d y\right] \\
& -\left(\frac{2}{h}\right)\left(\frac{2}{S}\right)\left[\int_{0}^{h} \int_{0}^{S} \sum_{q=1}^{Q} B_{q} \frac{\sinh \left(N_{q} X\right)}{\sinh \left(N_{q} S\right)} \sin \left(N_{q} y\right) \sin \left(N_{m} X\right) \sin \left(N_{n} y\right) d X d y\right] \\
& -\left(\frac{2}{h}\right)\left(\frac{2}{S}\right)\left[\int_{0}^{h} \int_{0}^{S} \sum_{p=1}^{P} C_{p} \frac{\sinh \left[N_{p}(S-X)\right]}{\sinh \left(N_{p} S\right)} \sin \left(N_{p} y\right) \sin \left(N_{m} X\right) \sin \left(N_{n} y\right) d X d y\right] .
\end{aligned}
$$

Calling the first, second and third integrals on the right-hand side of eqn (16) as $I^{1}, I^{2}$ and $I^{3}$, respectively, the equation then can be written in a concise form as

$$
A_{m n}=I^{1}+I^{2}+I^{3} \text {. }
$$

The aforementioned integrals, upon simplification, give

$$
I^{1}=\left[\frac{4 \delta_{0}}{h S N_{m} N_{n}}\right]\left[\cos \left(N_{m} S\right)-1\right]
$$

and for $q=n$

and for $q \neq n$

$$
I^{2}=\left(\frac{2}{S}\right) \sum_{q=1}^{Q} B_{q}\left[\frac{N_{m}}{\left(N_{m}\right)^{2}+\left(N_{q}\right)^{2}}\right] \cos \left(N_{m} S\right)
$$

$$
\begin{aligned}
I^{2}= & \left(\frac{4}{h S}\right) \sum_{q=1}^{Q} B_{q}\left[\frac{N_{m} \cos \left(N_{m} S\right)}{\left(N_{m}\right)^{2}+\left(N_{q}\right)^{2}}\right]\left\{\frac{1}{2\left(N_{q}-N_{n}\right)} \sin \left[\left(N_{q}-N_{n}\right) h\right]\right. \\
& \left.-\frac{1}{2\left(N_{q}+N_{n}\right)} \sin \left[\left(N_{q}+N_{n}\right) h\right]\right\}
\end{aligned}
$$

for $p=n$

and for $p \neq n$

$$
I^{3}=-\left(\frac{2}{S}\right) \sum_{p}^{P} C_{p}\left[\frac{N_{m}}{\left(N_{m}\right)^{2}+\left(N_{p}\right)^{2}}\right]
$$

$$
\begin{gathered}
I^{3}=-\left(\frac{4}{h S}\right) \sum_{p=1}^{P} C_{p}\left[\frac{N_{m}}{\left(N_{m}\right)^{2}+\left(N_{p}\right)^{2}}\right]\left\{\frac{1}{2\left(N_{p}-N_{n}\right)} \sin \left[\left(N_{p}-N_{n}\right) h\right]\right. \\
\left.-\frac{1}{2\left(N_{p}+N_{n}\right)} \sin \left[\left(N_{p}+N_{n}\right) h\right]\right\} .
\end{gathered}
$$

Thus, all the constants of eqn (5) are now being evaluated, and the flow problem of Fig. 1 is hence solved. It should be noted that the infinite series of eqn (5) converges as the ratios of the hyperbolic functions in the first two terms of the equations are always less than or equal to one and all the 
Fourier expansions carried out for determining the coefficients of the series converge, these expansions being Fourier expansions of continuous functions only. It should be noted that for $H_{1}=H_{3}$, the flow will become symmetrical with respect to the centroidal axis $F B$ of Fig. 1 and the proposed hydraulic head will then yield the same head distribution for the half flow domain $O A B F G O$ of Fig. 1 as can be obtained from the analytical model of Barua and Alam [20] for the same flow space.

The steady state expression for the hydraulic head function can be obtained from eqn (5) by simply allowing the time variable in it to go to infinity. It should be noted that this will cause the exponential term in it to vanish, leaving behind only the steady-state terms of the series. Thus, the steady-state hydraulic head expression for the flow problem of Fig. 1 can be expressed as

$$
\varphi^{(s t)}=\sum_{q=1}^{Q} B_{q} \frac{\sinh \left(N_{q} X\right)}{\sinh \left(N_{q} S\right)} \sin \left(N_{q} y\right)+\sum_{p=1}^{P} C_{p} \frac{\sinh \left[N_{p}(S-X)\right]}{\sinh \left[N_{p} S\right]} \sin \left(N_{p} y\right)+\delta_{0},
$$

where the superscript 'st' denotes that it is applicable only to the steady-state situation. To evaluate the steady-state stream function from the steady hydraulic head function as given by eqn (23), the following relations [22]

and

$$
\sqrt{K_{x} K_{y}} \frac{\partial \varphi}{\partial X}=\frac{\partial \psi}{\partial y}
$$

$$
\sqrt{K_{x} K_{y}} \frac{\partial \varphi}{\partial y}=-\frac{\partial \psi}{\partial X}
$$

can be made use of, where $\psi$ is the stream function.

Application of the aforementioned equations to eqn (23) gives the stream function for the flow domain as

$$
\begin{aligned}
\psi= & -\left(\sqrt{K_{x} K_{y}}\right) \sum_{q=1}^{Q} B_{q} \frac{\cosh \left(N_{q} X\right)}{\sinh \left(N_{q} S\right)} \cos \left(N_{q} y\right) \\
& +\left(\sqrt{K_{x} K_{y}}\right) \sum_{p=1}^{P} C_{p} \frac{\cosh \left[N_{p}(S-X)\right]}{\sinh \left(N_{p} S\right)} \cos \left(N_{p} y\right) \\
& +\left(\sqrt{K_{x} K_{y}}\right) \sum_{q=1}^{Q} B_{q} \frac{\cosh \left(N_{q} \varepsilon\right)}{\sinh \left(N_{q} S\right)}-\left(\sqrt{K_{x} K_{y}}\right) \sum_{p=1}^{P} C_{p} \frac{\cosh \left[N_{p}(S-\varepsilon)\right]}{\sinh \left(N_{p} S\right)},
\end{aligned}
$$

where it is assumed that the zero stream line passes through the point $(\varepsilon, 0)$ in the transformed domain. Furthermore, eqn (26) can also be used to express the normalized form of the stream function, $\psi^{n}$, as

$$
\psi^{n}=\frac{\psi(X, y)}{\psi(S-\varepsilon, 0)},
$$

where the denominator of eqn (27) can be estimated by putting $X=S-\varepsilon$ and $y=0$ in eqn (26).

It is worth mentioning at this point that the solution provided here is different from the general solution provided by Barua and Alam [19] for the transient ditch drainage problem as, unlike the latter, it does not include a variable ponding field over its surface. Of course, a variable depth of ponding allows a greater control [19] on the leaching process of a salt-affected soil in comparison to 
a situation when the soil is being subjected to a uniform depth of ponding. However, the general solution also demands a much higher computational effort in its use as compared to the use of the relatively simple model presented here. Furthermore, since a uniform depth of ponding is relatively easy to be introduced and maintained than the providence and maintenance of a variable ponding depth over the surface of a soil, the solution presented here is also expected to be relatively easier to be applied in actual field situations as compared to the use of the general solution [19].

\section{DISCUSSION}

In order to test the accuracy of the developed model, the predicted steady-state hydraulic heads and normalized streamlines specific to a flow situation of Fig. 1 were first compared with the corresponding values obtained from the steady-state ditch drainage model of Kirkham [14]. This is because the transient ditch drainage problem considered here reduces to that of Kirkham's [14] drainage problem under steady-state conditions and as such for such a condition predictions from both these models must match. From Fig. 2, it can be seen that both these solutions are indeed predicting identical hydraulic head contours and normalized streamlines for the chosen steady ponded drainage situation, thereby proving that the analytical model developed here is a correct one.

As an alternate check on the proposed solution, a numerical check on it was also carried out using the Processing MODFLOW [23] platform. A hypothetical drainage situation as shown in Fig. 2 was simulated with the help of 152 rows, 102 columns and 22 layers, where the distance between the northern and southern boundaries of the model was taken as $15 \mathrm{~m}$. Thus, the size of each of the grid cell considered for modeling was $0.1 \mathrm{~m} \times 0.1 \mathrm{~m} \times 0.05 \mathrm{~m}$. The cells falling in the vertical planes of the 1 st and the 102 nd columns were used to represent the ditches and the cells falling on the vertical planes of the 1 st and the 152 nd rows in between the 1 st and the 102nd columns and from the 1 st to the 21st layers were used to represent the northern and southern boundaries of the flow domain. The

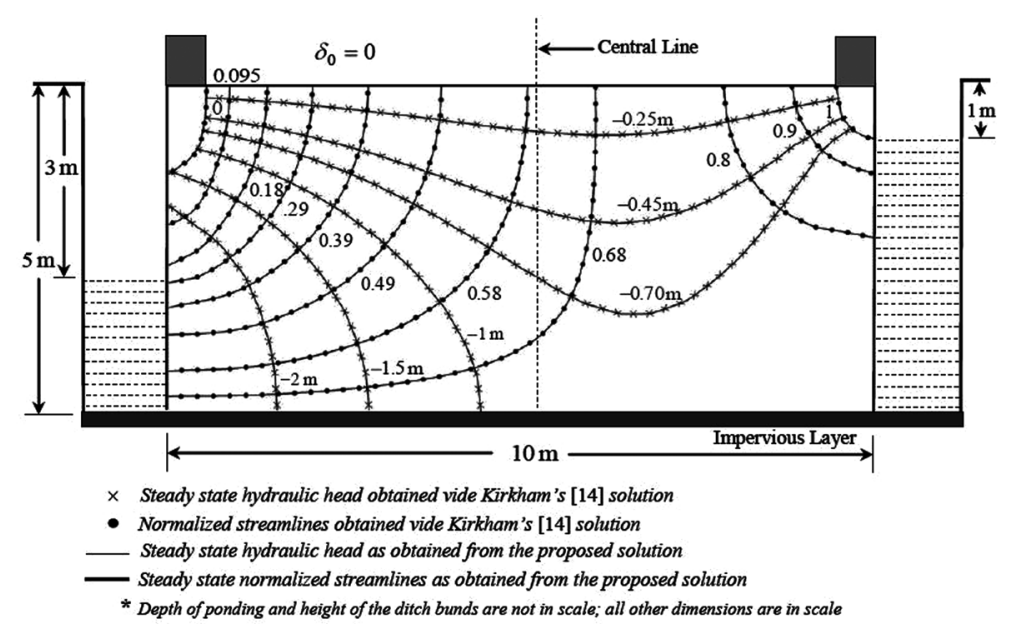

Figure 2: Comparison of lines of equal hydraulic head and normalized streamlines as obtained from the proposed steady-state solution of the flow problem of Fig. 1 with corresponding values obtained from the analytical solution of Kirkham [14] for an isotropic soil when the flow parameters of Fig. 1 are taken as $h=5 \mathrm{~m}, H_{1}=3 \mathrm{~m}, H_{3}=1 \mathrm{~m}, S_{\mathrm{a}}=20 \mathrm{~m}, \varepsilon_{\mathrm{a}}=0.5 \mathrm{~m}$, $\delta_{0}=0$, and $S_{\mathrm{s}}=0.001 \mathrm{~m}^{-1}$. 
Northern and Southern boundaries were taken as impervious and were simulated by making all the cells in these boundaries inactive. The bottom impervious layer was represented by treating all the cells of the 22nd layer as inactive and the two ditch banks (of width $0.1 \mathrm{~m}$ each) on the left and the right ditches were simulated by treating all the cells of the 2 nd and the 101st columns in between the 1 st and the 152 nd rows of the 1st layer as inactive. To simulate the surface of seepage and the water level height of $0.5 \mathrm{~m}$ in the left ditch, the cells falling on the 1 st column of all the rows in the 1st layer were assigned a fixed value of $0 \mathrm{~m},-0.05$ in the 2 nd layer, -0.1 in the 3rd layer and so on up to the 10th layer after which a constant value of $-0.5 \mathrm{~m}$ was assigned to all the cells running up to the 21st layer. In a similar way, a height of $0.25 \mathrm{~m}$ water level was assigned for the right ditch. With the aforementioned model structure in place and inputting the isotropic conductivity and the specific storage of the soil as $0.5 \mathrm{~m} /$ day and $0.001 \mathrm{~m}^{-1}$, respectively, in all the active cells, a transient MODFLOW simulation was carried out for the considered drainage situation and the numerically obtained hydraulic heads for two time steps were then compared with the corresponding values obtained using the proposed solution. Figure 3 shows such a comparison. As can be observed, the predicted analytical heads match very closely with the numerical counterparts, thereby showing once again the rightness of the proposed model. It should be noted that the numerical results presented in Fig. 3 were the ones measured in the vertical plane passing through the 75 th row (i.e. at halfway distance between the northern and the southern boundaries of the model) of the model - this was done to eliminate the boundary effects of the northern and the southern boundaries of the flow domain in order that a two-dimensional flow situation prevailed in the computational plane. The measurements of the hydraulic head contours on such a plane in the MODFLOW model were essential for comparison with the analytical results as the model proposed here is being developed by assuming the flow to be two-dimensional in nature.

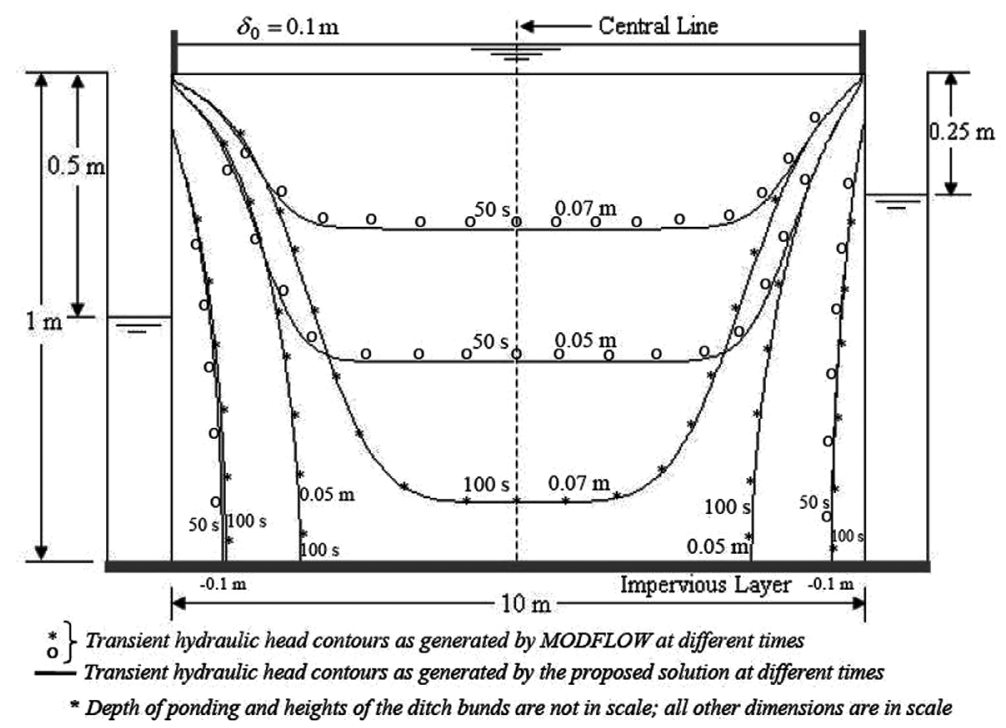

Figure 3: Comparison of hydraulic head contours as obtained from the proposed solution for a flow situation of Fig. 1 as shown with the corresponding MODFLOW generated contours at a few time intervals when $\varepsilon_{\mathrm{a}}=0.1 \mathrm{~m}$ and the soil parameters are taken as $S_{\mathrm{s}}=0.001 \mathrm{~m}^{-1}$ and $K_{x} / K_{y}=1 / 1\left(K_{\mathrm{x}}=0.5 \mathrm{~m} /\right.$ day, $K_{\mathrm{y}}=0.5 \mathrm{~m} /$ day $)$. 


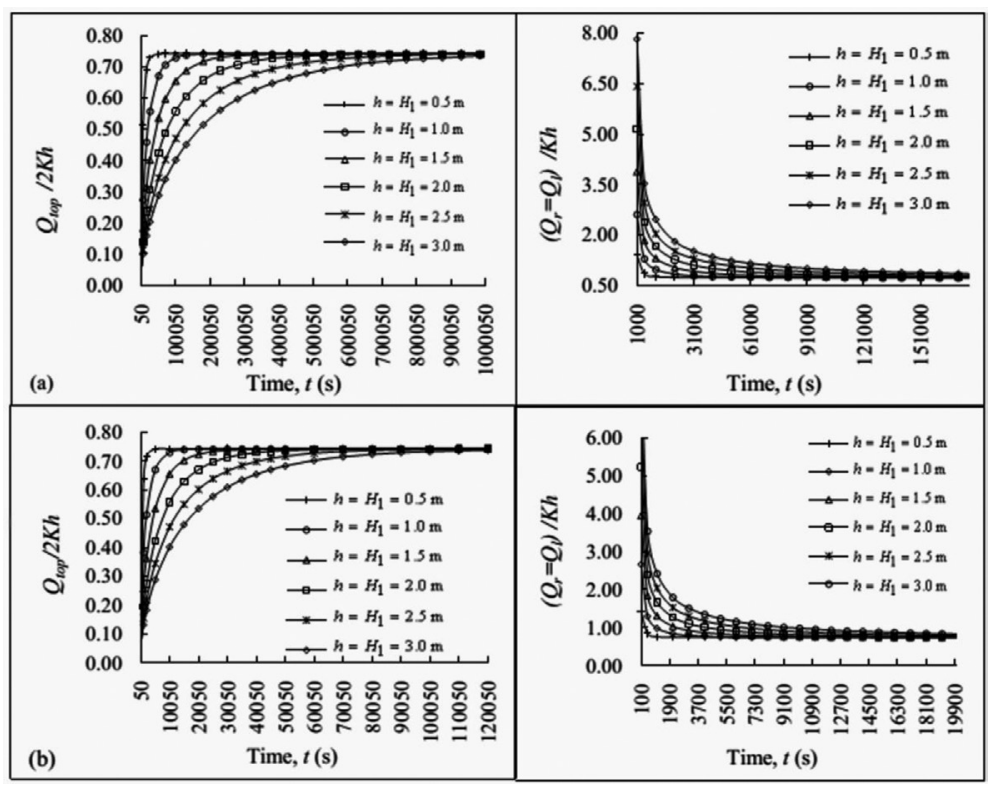

Figure 4: Variation of $Q_{\text {top }} / 2 K h$ and $\left(Q_{r}=Q_{1}\right) / K h$ ratios with time when the variables of the problem are taken as $h=H_{1}$ (i.e. ditches are running empty), $S_{a}=100 \mathrm{~m}$ (theoretically infinite), $\delta_{0}=0, \varepsilon_{a}=0, K_{x} / K_{y}=25 / 1\left(K_{x}=0.0254 \mathrm{~m} /\right.$ day, $K_{y}=0.001016 \mathrm{~m} /$ day $)$ and (a) $S_{s}=0.001 \mathrm{~m}^{-1}$ and (b) $S_{s}=0.0001 \mathrm{~m}^{-1}$.

From Fig. 4, it can be seen that the transient duration of flow from a ponded field into an array of equally spaced ditch drains may be considerable for a soil characterized by low horizontal and vertical hydraulic conductivities and a high anisotropy ratio, especially when the specific storage of the soil is high and the drains are relatively deep. The effect of the specific storage on transient state duration is also clearly reflected in Figs 4(a) and 4(b), where, as may be observed, a tenfold decrease of the specific storage has resulted in a substantial decrease in the transient state durations of all the considered drainage situations. As the hydraulic conductivity of many field soils may be quite low [24] and the occurrence of soils with high anisotropy ratio is also pretty common in nature [25], it is obvious that the ponded leaching of such soils will mostly be a transient process and considerable time may be required to leach such soils.

Figure 5 shows that the uniformity of the top discharge function (see Appendix) is fairly good at early times of simulation of a ditch drainage system subjected to a uniform depth of ponding and that this uniformity falters with the progress of time, specifically in situations in which the anisotropy ratio of the soil is low. It can also be observed from Fig. 6 that the steady-state streamline distribution in the flow domain is highly sensitive to the anisotropy ratio of a soil. An increase in the anisotropy ratio of a soil has a tendency to uncoil the streamlines and a decrease in the anisotropy ratio causes them to come close to each other; thus, in a soil with a high anisotropy ratio, the streamlines are more uniformly distributed in a ponded drainage space in comparison to a low anisotropy soil where the flow is mostly concentrated to regions close to the drains only. This is understandable as an increase in the anisotropy ratio of a soil (by assuming the other parameters of the problem to remain the same) brings about a decrease in horizontal resistance to water movement in a homogeneous and anisotropic soil, resulting in more spread of the streamlines in a ponded drainage space. As the 

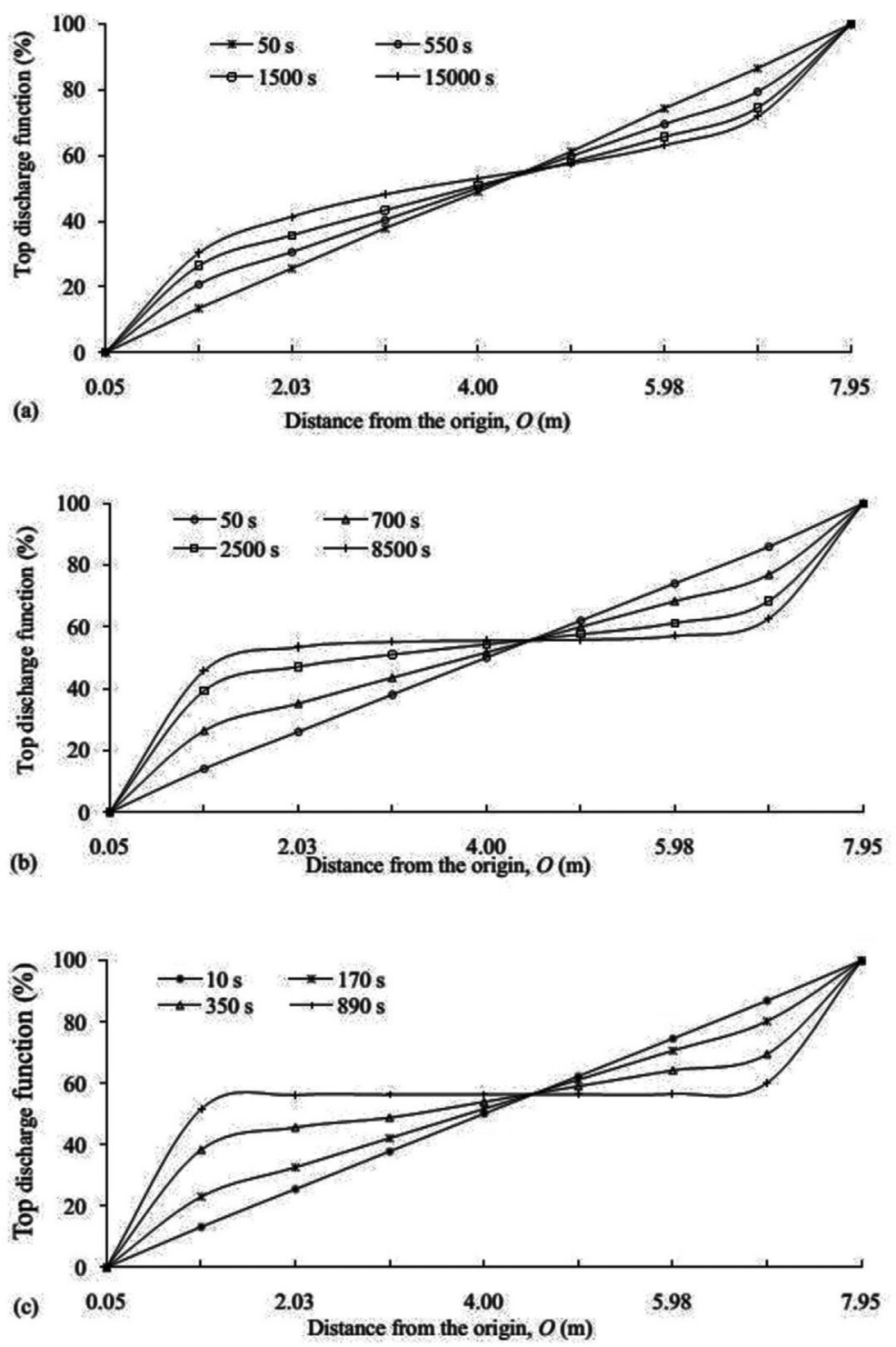

Figure 5: Variation of top discharge function with distance as measured from the origin $O$ at different times when the flow parameters of Fig. 1 are taken as $h=1 \mathrm{~m}, H_{1}=0.5 \mathrm{~m}, H_{3}=0.25 \mathrm{~m}$, $\delta_{0}=0.2 \mathrm{~m}, S=8 \mathrm{~m}, S_{s}=0.001 \mathrm{~m}^{-1}, \varepsilon_{\mathrm{a}}=0.05 \mathrm{~m}$ and (a) $K_{x} / K_{y}=10 / 1\left(K_{x}=0.0254 \mathrm{~m} /\right.$ day, $K_{y}=0.00254 \mathrm{~m} /$ day $)$, (b) $K_{x} / K_{y}=1 / 1\left(K_{x}=0.0254 \mathrm{~m} /\right.$ day, $K_{y}=0.0254 \mathrm{~m} /$ day $)$ and (c) $K_{x} / K_{y}=1 / 10\left(K_{x}=0.0254 \mathrm{~m} /\right.$ day, $K_{y}=0.254 \mathrm{~m} /$ day $)$.

horizontal hydraulic conductivity of most soils in nature is generally higher than the vertical hydraulic conductivity, the uniformity of leaching under a ponded drainage situation is generally assisted by the inherent orientations of the directional conductivities (i.e. horizontal and vertical hydraulic conductivities) of a soil. Furthermore, it may also be observed that the water level heights between 

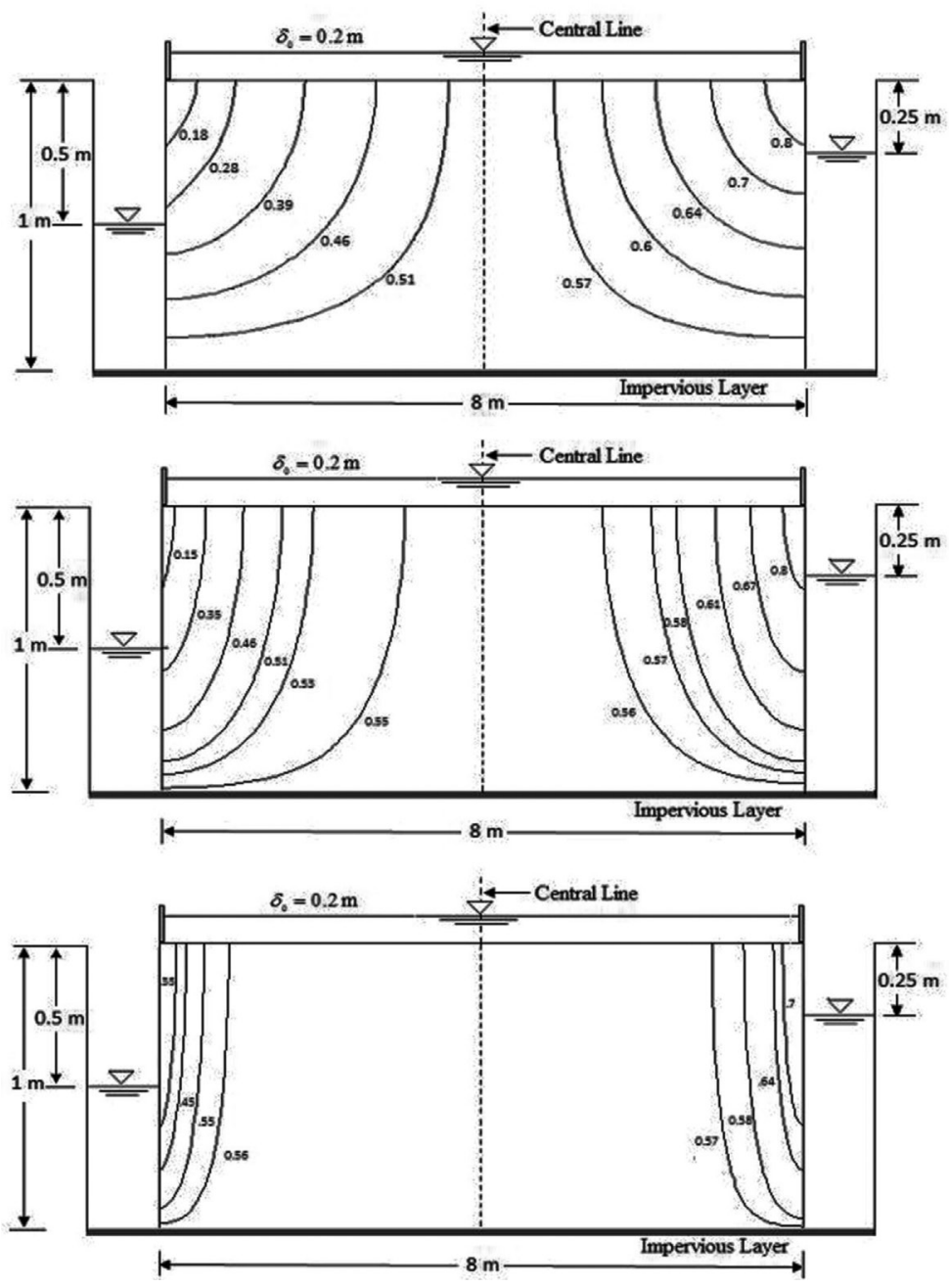

Figure 6: Steady-state normalized streamlines corresponding to a few flow situations of Fig. 1 when (a) $K_{x} / K_{y}=10 / 1\left(K_{x}=0.1 \mathrm{~m} /\right.$ day, $K_{y}=0.01 \mathrm{~m} /$ day $)$; (b) $K_{x} / K_{y}=1 / 1\left(K_{x}=0.1 \mathrm{~m} /\right.$ day, $K_{y}=0.1 \mathrm{~m} /$ day $)$ and (c) $K_{x} / K_{y}=1 / 10\left(K_{x}=0.1 \mathrm{~m} /\right.$ day, $K_{y}=1 \mathrm{~m} /$ day $)$ and $\varepsilon_{a}=0.05 \mathrm{~m}$, and the other parameters are as shown.

the adjacent drains also influence the streamline profiles in a drainage space - the drain with the lower water level can be seen to have a greater share of flow into it as compared to the drain with the higher water level. This is easy to understand as a decrease in the water level of a ditch by a certain depth from a reference location causes the potential difference between the ponded field and the ditch to increase in the lowered portion of the ditch, resulting in more water to flow to the ditch as compared to the situation when the ditch level is being held constant in the referenced position.

Figure 7 shows the upper limit of fall of surface water with time when the parameters of the drainage problem are taken as $h=1.0 \mathrm{~m}, H_{1}=0.5 \mathrm{~m}, H_{3}=0.25 \mathrm{~m}, S_{a}=20 \mathrm{~m}, \varepsilon_{a}=0.05 \mathrm{~m}, \delta_{0}=0.1 \mathrm{~m}$, $S_{s}=0.001 \mathrm{~m}^{-1}$ and $K_{x}=K_{y}=1 \mathrm{~m} /$ day. It is to be noted that an upper limit of fall of water at the 


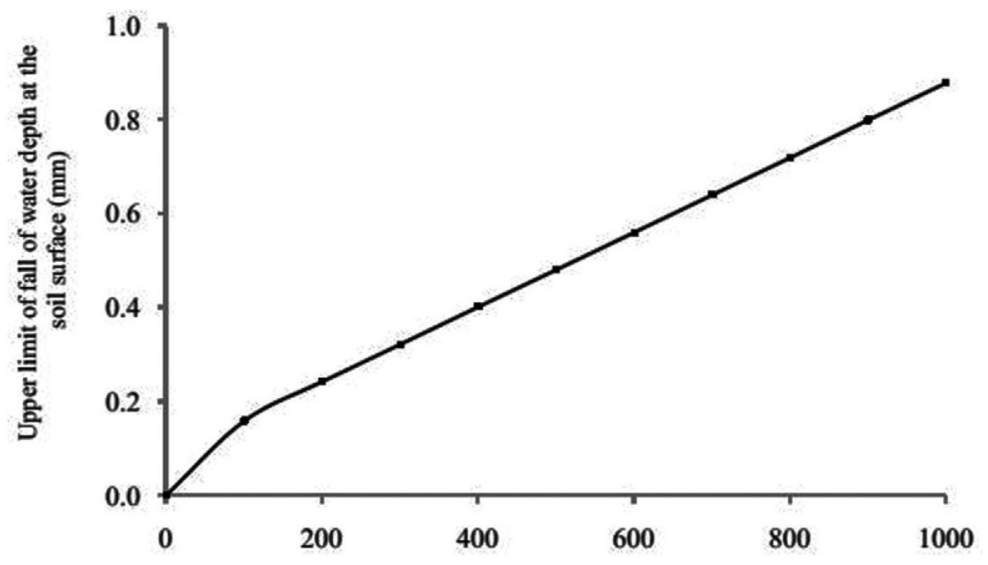

Figure 7: Variation of upper limit of fall of water at the surface of the soil when the parameters of the flow problem are taken as $h=1.0 \mathrm{~m}, H_{1}=0.5 \mathrm{~m}, H_{3}=0.25 \mathrm{~m}, S_{a}=20 \mathrm{~m}, \varepsilon_{\mathrm{a}}=0.05 \mathrm{~m}$, $\delta_{0}=0.1 \mathrm{~m}, S_{s}=0.001 \mathrm{~m}^{-1}$ and $K_{x}=K_{y}=1 \mathrm{~m} /$ day.

surface of the soil corresponding to a simulation time can be determined by first estimating the volume of water seeping through the surface of the soil during that time and then dividing this volume by the surface area [in this instance, $(20-0.1) \times 1 \mathrm{~m}^{2}$ ] through which this volume seeps through the soil. This fall is called an upper limit as the volume of seepage used for calculating this fall has been estimated by assuming the ponding depth to remain constant during the time of simulation. In reality, however, the fall of water levels would be less than those estimated by this means as the depth of ponding will not be a constant during the time of simulation but would progressively decrease with the increase of time. From Fig. 7, it can be readily seen that the rate of fall of water level at the surface for the considered drainage situation decreases with the increase in time and this rate then stabilizes and attains a constant rate after the system reaches steady state. Thus, flow in a ponded ditch drainage system is never truly a steady-state flow and, as mentioned before, the transient state duration of a ponded drainage system may be quite large, particularly when the drains are installed in a soil with low hydraulic conductivity and high specific storage.

\section{CONCLUSIONS}

An analytical model has been derived for predicting transient flow into a network of equally spaced ditch drains in a homogeneous and anisotropic soil receiving water from a ponded field, the soil being underlain by an impermeable barrier. The solution can tackle both equal as well unequal water level heights in between the adjacent drains and can also account directly for the anisotropy of a soil profile. The accuracy of the developed solution has been tested by comparing steady-state predictions of hydraulic heads and normalized stream lines obtained from it for a specific drainage situation with identical results obtained from the analytical work of Kirkham [14]. A MODFLOW check on the developed model has also been performed. The study demonstrates that the time taken to attain steady state by a ponded drainage system may be considerable if the drains are being installed in a soil having low values of horizontal and vertical hydraulic conductivity and high values of anisotropy ratio and specific storage. This is especially true, if the drains are being installed relatively deeper inside the soil. The study also shows that the rate of flow to a drain is sensitive to the level of water in the drain and that the uniformity of surface flux at early times of a simulation of a ponded 
ditch drainage system is relatively much better than that at later times, particularly for situations where the anisotropy ratio of the soil is high. Considering other factors to remain the same, a high anisotropy ratio causes the streamline to spread apart from the drains and a low anisotropy ratio makes them cluster close to each other near the drains. Thus, leaching a salt-affected soil with a high anisotropy ratio using a ponded drainage system will result in a more uniform leaching of the soil profile as compared to the case when the anisotropy ratio of the soil is low. The proposed solution can also be employed to design drainage networks for reclaiming a waterlogged soil within a stipulated time and to gain insight into the hydraulics of a ponded ditch drainage system in both steady as well as transient zones of simulation of the system.

\section{APPENDIX}

The discharge per unit length into one side (i.e. through face $O A$ of Fig. 1) of the left ditch, $Q_{l}$, can be calculated by applying the Darcy's law on the concerned face - the pertinent expression works out to be

$$
\begin{aligned}
Q_{l}= & \left(\sqrt{K_{x} K_{y}}\right) \sum_{q=1}^{Q} B_{q} \frac{1}{\sinh \left(N_{q} S\right)}-\left(\sqrt{K_{x} K_{y}}\right) \sum_{p=1}^{P} C_{p} \frac{\cosh \left(N_{p} S\right)}{\sinh \left(N_{p} S\right)} \\
& +\left(\sqrt{K_{x} K_{y}}\right) \sum_{m=1}^{M} \sum_{n=1}^{N} A_{m n}\left[\frac{N_{m}}{N_{n}}\right] \exp \left[\frac{-\left(\lambda_{m n}\right)^{2} t}{\left(K_{1}\right)^{2}}\right] .
\end{aligned}
$$

Similarly, an expression of discharge per unit length from one side of the right ditch, $Q_{r}$, can also be determined by making use of Darcy's law on the face $C D$ of Fig. 1 - the relevant expression for the same can be written as:

$$
\begin{aligned}
Q_{r}= & -\left(\sqrt{K_{x} K_{y}}\right) \sum_{q=1}^{Q} B_{q} \frac{\cosh \left(N_{q} S\right)}{\sinh \left(N_{q} S\right)}+\left(\sqrt{K_{x} K_{y}}\right) \sum_{p=1}^{P} C_{p} \frac{1}{\sinh \left(N_{p} S\right)} \\
& -\left(\sqrt{K_{x} K_{y}}\right) \sum_{m=1}^{M} \sum_{n=1}^{N} A_{m n}\left[\frac{N_{m}}{N_{n}}\right] \cos \left(N_{m} S\right) \exp \left[\frac{-\left(\lambda_{m n}\right)^{2} t}{\left(K_{1}\right)^{2}}\right] .
\end{aligned}
$$

The discharge coming from the surface of the soil in between the adjacent ditches per unit length of the ditches, $Q_{\text {topX }}$, from a distance of $X$ from the origin of Fig. 1 can be estimated by making an application of Darcy's law in the desired portion of the flow domain - the concerned expression works out to be

$$
\begin{aligned}
Q_{\text {top } X}= & -\left(\sqrt{K_{x} K_{y}}\right) \sum_{q=1}^{Q} B_{q} \frac{1}{\sinh \left(N_{q} S\right)}\left[\cosh \left(N_{q} X\right)-\cosh \left(N_{q} \varepsilon\right)\right] \\
& +\left(\sqrt{K_{x} K_{y}}\right) \sum_{p=1}^{P} C_{p} \frac{1}{\sinh \left(N_{p} S\right)}\left\{\cosh \left[\left(N_{p}(S-X)\right]-\cosh \left[N_{p}(S-\varepsilon)\right]\right\}\right. \\
& +\left(\sqrt{K_{x} K_{y}}\right) \sum_{m=1}^{M} \sum_{n=1}^{N} A_{m n}\left[\frac{N_{n}}{N_{m}}\right] \exp \left[\frac{-\left(\lambda_{m n}\right)^{2} t}{\left(K_{1}\right)^{2}}\right]\left[\cos \left(N_{m} X\right)-\cos \left(N_{m} \varepsilon\right)\right],
\end{aligned}
$$


where $\varepsilon=\left(K_{y} / K_{x}\right)^{1 / 2} \varepsilon_{a}$.

Now, the total discharge per unit length for the entire distance in between the inner embankments between the adjacent ditches, $Q_{t o p}$, can be easily worked out from eqn (A3) by simply substituting $X=S-\varepsilon$ in it; thus,

$$
\begin{aligned}
Q_{\text {top }}= & -\left(\sqrt{K_{x} K_{y}}\right) \sum_{q=1}^{Q} B_{q} \frac{1}{\sinh \left(N_{q} S\right)}\left\{\cosh \left[N_{q}(S-\varepsilon)\right]-\cosh \left(N_{q} \varepsilon\right)\right\} \\
& +\left(\sqrt{K_{x} K_{y}}\right) \sum_{p=1}^{P} C_{p} \frac{1}{\sinh \left(N_{p} S\right)}\left\{\cosh \left(N_{p} \varepsilon\right)-\cosh \left[N_{p}(S-\varepsilon)\right\}\right. \\
& +\left(\sqrt{K_{x} K_{y}}\right) \sum_{m=1}^{M} \sum_{n=1}^{N} A_{m n}\left[\frac{N_{n}}{N_{m}}\right] \exp \left[\frac{-\left(\lambda_{m n}\right)^{2} t}{\left(K_{1}\right)^{2}}\right]\left\{\cos \left[N_{m}(S-\varepsilon)\right]-\cos \left(N_{m} \varepsilon\right)\right\} .
\end{aligned}
$$

The fraction of the total discharge coming from the top of the field from a region extending to a distance $X$ from the origin $O, Q_{t o p X}^{f}$ (top discharge function), can also be calculated by simply dividing eqn (A5) by the expression of total discharge given by eqn (A6). Also, the volume of water seeping per unit length of the ditches through the faces $O A$ and $C D$ of the left and the right ditches of Fig. 1 can be evaluated by performing time integrals on the left and right discharge expressions [eqns (A1) and (A2)] in the interval $t$. Similarly, the volume of water seeping through the surface of the soil per unit length of the drains in between two adjacent drains in the time interval $t$ can be easily evaluated by performing a time integral on eqn (A4).

It should be noted that all the expressions related to the stream function and discharge will diverge for the case when $\delta_{0} \neq 0$ and $\varepsilon_{a}=0$. This is because, for such a situation, all these expressions will have a term like $\left(2 \delta_{0} / h\right) \sum_{p=1}^{P \rightarrow \infty} \operatorname{coth}\left(N_{p} S\right) / N_{p}$, an infinite series that diverges since $\operatorname{Lim}_{p \rightarrow \infty}\left|\operatorname{coth}\left(N_{p} S\right)\right|=1$ and $\left|\sum_{p=1}^{P \rightarrow \infty}\left(1 / N_{p}\right)\right| \rightarrow \infty$.

\section{REFERENCES}

[1] Manjunatha, M.V., Oosterbaan, R.J. Gupta, S.K., Rajkumar, H. \& Jansen, H., Performance of subsurface drains for reclaiming waterlogged saline under rolling topography in Tungabhadra irrigation project in India. Agricultural Water Management, 69, pp. 69-82, 2004. doi: http:// dx.doi.org/10.1016/j.agwat.2004.01.001

[2] Chahar, B.R. \&Vadodaria, G.P., Steady subsurface drainage of homogeneous soil by ditches. Proceedings of the ICE-Water Management, 161(WM6), pp. 303-311, 2008. doi: http://dx.doi. org/10.1680/wama.2008.161.6.303

[3] Chahar, B.R. \& Vadodaria, G.P., Drainage of ponded surface by an array of ditches. Journal of Irrigation and Drainage Engineering, 134(6), pp. 815-823, 2008. doi: http://dx.doi. org/10.1061/(asce)0733-9437(2008)134:6(815)

[4] Dielman, P.J. (ed.), Reclamation of Salt-Affected Soils in Iraq. Publication 11, International Institute for Land Reclamation and Improvement, Wageningen: The Netherlands, pp. 175, 1963. 
[5] Martinez Beltran, J., Drainage and Reclamation of Salt Affected Soils in the Bardenas Area, Spain. Publication 24, International Institute for Land Reclamation and Improvement, Wageningen: The Netherlands, 1978.

[6] Zaslavsky, D., Drainage for salt leaching. Proceedings of the International Drainage Workshop, ed. J. Wesseling, International Institute for Land Reclamation and Improvement, Wageningen: The Netherlands, 25, pp. 664-685, 1979.

[7] Abrol, I.P., Yadav J.S.P. \& Massoud, F.I., Salt-Affected Soils and Their Management. FAO Land and Water Development Division, FAO Soils Bulletin, Soil Resources, Management and Conservation Service, issue 39, p. 131, 1988.

[8] van Hoorn, J.W. \& van Alphen, J.G., Salinity control. Drainage Principles and Applications, ed. H.P. Ritzema, 2nd edn., Publication 16, International Institute for Land Reclamation and Improvement, Wageningen: The Netherlands, pp. 533-600, 1994.

[9] Rao,K.V.G.K.\&Leeds-Harrison,P.B.,Desalination with subsurfacedrainage.AgriculturalWater Management, 19, pp. 303-311, 1991. doi: http://dx.doi.org/10.1016/0378-3774(91)90023-C

[10] Jia, X., Dukes, M.D., Jacobs, J.M. \& Irmak, S., Weighing lysimeters for evapotranspiration research in a humid environment. Transactions of American Society of Agricultural Engineers, 49(2), pp. 401-412, 2006. doi: http://dx.doi.org/10.13031/2013.20414

[11] Kirkham, D. \& van Bavel, C.H.M., Theory of seepage into auger holes. Soil Science Society of America Proceedings, 13, pp. 75-82, 1948.

[12] Kirkham, D., Seepage into ditches in the case of a plane water table and an impervious substratum. Transactions of American Geophysical Union, 31(3), pp. 425-430, 1950. doi: http:// dx.doi.org/10.1029/tr031i003p00425

[13] Fukuda, H., Underdrainage into ditches in soil overlying an impervious substratum. Transactions of American Geophysical Union, 38(5), pp. 730-739, 1957. doi: http://dx.doi.org/10.1029/ tr038i005p00730

[14] Kirkham, D., Seepage of leaching water into drainage ditches of unequal water level height. Journal of Hydrology, 3, 207-224, 1965. doi: http://dx.doi.org/10.1016/0022-1694(65)90081$\underline{8}$

[15] Warrick, A.W. \& Kirkham, D., Two-dimensional seepage of ponded water to full ditch drains. Water Resources Research, 5(3), pp. 685-693, 1969. doi: http://dx.doi.org/10.1029/ wr005i003p00685

[16] Youngs, E.G., Seepage to ditches from a ponded surface. Journal of Hydrology, 161, pp. 145-154, 1994. doi: http://dx.doi.org/10.1016/0022-1694(94)90125-2

[17] Barua, G. \& Tiwari, K.N., Analytical solutions of seepage into ditches from ponded fields. Journal of Irrigation and Drainage Engineering, 121(6), pp. 396-404, 1995. doi: http://dx.doi. org/10.1061/(asce)0733-9437(1995)121:6(396)

[18] Chahar, B.R. \& Vadodaria, G.P., Steady subsurface drainage of ponded surface by an array of parallel ditches. Journal of Hydrologic Engineering, 17(8), pp. 895-908, 2012. doi: http:// dx.doi.org/10.1061/(asce)he.1943-5584.0000518

[19] Barua, G. \& Alam, W., An analytical solution for predicting transient seepage into ditch drains from a ponded field. Advances in Water Resouces, 52, pp. 78-92, 2013. doi: http://dx.doi. org/10.1016/j.advwatres.2012.09.002

[20] Barua, G. \& Alam, W., An analytical model for predicting transient flow into equally spaced ditch drains receiving water from a uniformly ponded field. The manuscript is scheduled to be published in the WIT Transactions on Ecology and the Environment, 171.

[21] Kirkham, D. \& Powers, W.L., Advanced Soil Physics. Wiley Interscience Inc.: New York, 1972. 
[22] Bear, J., Dynamics of Fluids in Porous media. American Elsevier Publishing Company Inc.: New York, p. 235, 1972.

[23] Chiang, W. \& Kinzelbach, W., 3D-Groundwater Modeling with PMWIN: A Simulation System for Modeling Groundwater Flow and Pollution. Springer-Verlag: Berlin, 2001.

[24] MacDonald, A.M., Maurice, L., Dobbs, M.R., Reeves, H.J. \& Auton, C.A., Relating in situ hydraulic conductivity, particle size and relative density of superficial deposits in a heterogeneous catchment. Journal of Hydrology, 434-435, pp. 130-141, 2012. doi: http://dx.doi. org/10.1016/j.jhydrol.2012.01.018

[25] Maasland, M., Theory of land drainage: soil anisotropy and land drainage. Drainage of Agricultural Lands, ed. J.N. Luthin, American Society of Agronomy, 7: Wisconsin, 1957. 